\section{Raw milk consumption and other early-life farm exposures and adult pulmonary function in the Agricultural Lung Health Study}

\author{
ABSTRACT \\ Literature suggests that early exposure to the \\ farming environment protects against atopy \\ and asthma; few studies have examined \\ pulmonary function. We evaluated associations \\ between early-life farming exposures and \\ pulmonary function in 3061 adults (mean \\ age $=63$ ) from a US farming population \\ using linear regression. Childhood raw milk \\ consumption was associated with higher \\ $\mathrm{FEV}_{1}(\beta=49.5 \mathrm{~mL}, 95 \% \mathrm{Cl} 2.8$ to $96.1 \mathrm{~mL}$, \\ $\mathrm{p}=0.04)$ and $\mathrm{FVC}(\beta=66.2 \mathrm{~mL}, 95 \% \mathrm{Cl}$ \\ 13.2 to $119.1 \mathrm{~mL}, p=0.01)$. We did not find \\ appreciable associations with other early- \\ life farming exposures. We report a novel \\ association between raw milk consumption \\ and higher pulmonary function that lasts into \\ older adulthood.
}

\section{INTRODUCTION}

Previous literature suggests that the farming environment protects against childhood asthma and allergy. ${ }^{1}$ Along with farm animal contact, raw milk consumption has been an exposure of particular interest. ${ }^{2}$ In adults, atopy and, to a lesser degree, asthma have been associated with the earlylife farm environment. ${ }^{3}$ Studies of early-life farming exposure and adult pulmonary function are few and none have investigated raw milk. ${ }^{4-6}$ The two largest studies reported higher $\mathrm{FEV}_{1}$ or FVC among adults raised on farms. ${ }^{4}$ Here we investigate associations between early-life farm exposures, including raw milk consumption, and pulmonary function in an adult US farming population.

\section{METHODS}

As described previously, ${ }^{3} 7$ the Agricultural Lung Health Study (ALHS) is a case-control study of current asthma among farmers and their spouses nested within the prospective Agricultural Health Study (AHS data releases P3REL201209.00, PIREL201209.00 and AHSREL201304.00). Pulmonary function $\left(\mathrm{FEV}_{1}, \mathrm{FVC}\right.$ and $\left.\mathrm{FEV}_{1} / \mathrm{FVC}\right)$ was measured by trained staff during in-home visits with an EasyOne Spirometer (NDD Medical Technologies, Chelmsford, Massachusetts, USA) based on the American Thoracic Society guidelines. Information on early-life exposures was obtained by questionnaire. Raw milk consumption was determined from the following prompt and question: 'We are also interested in whether you ever drank raw or unpasteurized milk, also referred to as 'farm milk'. Have you ever drank raw milk?' Wording of questions for other early-life exposures, including timing of raw milk consumption, is available in online supplementary table 1 . This analysis includes 3061 individuals (from 3301 enrolled in ALHS during 2009-2013) with complete data on early-life exposures and covariates, and whose FVC values had a quality attribute of ' $\mathrm{C}$ ' or better. ${ }^{8}$

Using linear regression we estimated betas and 95\% CI for associations between early-life exposures and $\mathrm{FEV}_{1}$ (in $\mathrm{mL}$ ), FVC (in $\mathrm{mL}$ ) and $\mathrm{FEV}_{1} / \mathrm{FVC}$ (as a percent) adjusting for age, age ${ }^{2}$, height, height ${ }^{2}$, sex, race (white, non-white), state (Iowa, North Carolina), smoking status (current, former, never), pack-years of cigarette smoking and current asthma status (case, non-case). FVC models also included weight. Covariates were selected based on previous research on modelling pulmonary function ${ }^{9}$ and ALHS analyses. ${ }^{37}$ Since we analysed actual values for $\mathrm{FEV}_{1}$ and $\mathrm{FVC}$, we included all variables from standard prediction equations, ${ }^{9}$ including race despite the small number of non-white individuals in ALHS.

\section{RESULTS}

Approximately half of participants were male farmers and half were female spouses (see online supplementary table 2). Most (98.4\%) were white and $71.0 \%$ were from Iowa. The mean age was 63 years. Few currently smoked; $66.5 \%$ never smoked. Three-fourths (73.8\%) reported their family lived on a farm when they were born, $60.9 \%$ that their mother worked with farm animals while pregnant with them (in utero exposure) and $75.6 \%$ reported contact with farm animals before age 6 years (table 1 ).

Raw milk consumption was common (73.4\%), and most who drank it (84.1\%) started before age 6 (tables 1 and 2). Raw milk consumption was associated with higher $\mathrm{FEV}_{1}(\beta=49.5 \mathrm{~mL}, 95 \% \mathrm{CI} 2.8$ to $96.1 \mathrm{~mL}, \mathrm{p}=0.04)$ and FVC $(\beta=66.2 \mathrm{~mL}$, $95 \%$ CI 13.2 to $119.1 \mathrm{~mL}, \quad \mathrm{p}=0.01$; table 1) but not $\mathrm{FEV}_{1} / \mathrm{FVC} \quad(\beta=0.4 \%$, $95 \%$ CI -0.4 to $1.1 \%, \mathrm{p}=0.33$ ). Associations were most notable for raw milk consumption beginning before age 6 years $\left(\mathrm{FEV}_{1}\right.$ : $\beta=51.3 \mathrm{~mL}, 95 \%$ CI 2.8 to $99.8 \mathrm{~mL}, \mathrm{p}=0.04$; FVC: $\beta=76.7 \mathrm{~mL}, 95 \%$ CI 21.7 to $131.7 \mathrm{~mL}, \mathrm{p}=0.006$; table 2 ) but were also in the positive direction for the smaller group who started after. Estimates for raw milk consumption beginning before and after age 3 years were similar to age 6 estimates (table 2). Although ability to recall timing of events before age 3 years may be limited, when we examined starting raw milk consumption before age 2 years (1458 individuals), the results were slightly stronger $\left(\mathrm{FEV}_{1}: \beta=61.3 \mathrm{~mL}\right.$, 95\% CI 10.9 to $111.8 \mathrm{~mL}, \mathrm{p}=0.02$; FVC: $\beta=83.3 \mathrm{~mL}, 95 \%$ CI 26.1 to $140.5 \mathrm{~mL}$, $\mathrm{p}=0.004)$. Consuming raw milk as the main milk source in childhood $(79.3 \%$ of consumers) was most notably associated with higher FVC $(\beta=53.8 \mathrm{~mL}, 95 \% \mathrm{CI}$ 7.2 to $100.5 \mathrm{~mL}$ ), although the association was also in the positive direction for $\mathrm{FEV}_{1}$ ( $\beta=28.3 \mathrm{~mL}, 95 \% \mathrm{CI}-12.7$ to $69.3 \mathrm{~mL}$ ).

Among the 2246 individuals who ever drank raw milk, the majority $(n=2044$; 91.0\%) no longer drank it (stopped on average 45.0 years prior), while 168 (7.5\%) drank it within the last 10 years (stopped on average 3.3 years prior). Raw milk associations did not change when we accounted for consumption within the last 10 years or excluded 197 ever raw milk drinkers for whom we could not be certain that consumption started in childhood (ie, before age 18 years) (see online supplementary table $3)$. Among those starting before age 6 we could examine lifetime duration and found no association (see online supplementary table 3). Results for raw milk consumption were also virtually unchanged when we excluded 360 individuals with an FVC quality attribute of ' $C$ ' (see online supplementary table 3 ).

Raw milk associations were more apparent in the much larger group of non-asthmatics $\left(n=1936 ; \mathrm{FEV}_{1}\right.$ : $\beta=61.0 \mathrm{~mL}, 95 \%$ CI 4.9 to $117.1 \mathrm{~mL}$; FVC: $\beta=66.2 \mathrm{~mL}, 95 \%$ CI 0.9 to $131.5 \mathrm{~mL}$ ) than in asthmatics $\left(n=1125 ; \mathrm{FEV}_{1}: \beta=23.1 \mathrm{~mL}\right.$, $95 \%$ CI -59.3 to $105.5 \mathrm{~mL}$; FVC: $\beta=53.2 \mathrm{~mL}, 95 \% \mathrm{CI}-36.7$ to $143.0 \mathrm{~mL}$ ), but these differences were not statistically significant $\left(\mathrm{FEV}_{1}: \mathrm{p}_{\text {interaction }}=0.07 ; \mathrm{FVC}\right.$ : $\mathrm{p}_{\text {interaction }}=0.30$; see online supplementary table 4). In addition, raw milk associations among non-asthmatics were not materially altered by excluding individuals with childhood asthma $(n=25)$, childhood pneumonia $(n=166)$ or either $(n=184)$, suggesting that the associations were not driven by susceptibility to childhood respiratory illnesses. For example, the estimate for raw milk consumption and $\mathrm{FEV}_{1}$ among non-asthmatics was $61.1 \mathrm{~mL}$ after excluding individuals with either condition. Raw milk associations for $\mathrm{FEV}_{1}$ were more apparent in women $(\beta=58.0 \mathrm{~mL}, 95 \%$ CI 9.9 to $106.0 \mathrm{~mL})$ than men $(\beta=36.5 \mathrm{~mL}, 95 \% \mathrm{CI}$ -48.4 to $121.3 \mathrm{~mL}$ ), but this difference was of borderline statistical significance $\left(\mathrm{p}_{\text {interaction }}=0.05\right.$; see online supplementary 
Table 1 Associations between early-life farm exposures and pulmonary function in the Agricultural Lung Health Study, 2009-2013

\begin{tabular}{|c|c|c|c|c|c|c|c|}
\hline \multirow[b]{2}{*}{ Early-life exposures } & \multirow[b]{2}{*}{$\mathrm{N}$} & \multicolumn{2}{|l|}{$\mathrm{FEV}_{1}(\mathrm{~mL})$} & \multicolumn{2}{|l|}{ FVC (mL) } & \multicolumn{2}{|l|}{$\mathrm{FEV}_{1} / \mathrm{FVC}(\%)$} \\
\hline & & $\boldsymbol{\beta}(95 \% \mathrm{Cl})^{*}$ & $\mathrm{p}$ Value & $\boldsymbol{\beta}(95 \% \mathrm{Cl})^{*}$ & $\mathrm{p}$ Value & $\boldsymbol{\beta}(95 \% \mathrm{Cl})^{*}$ & $\mathrm{p}$ Value \\
\hline Total & 3061 & & & & & & \\
\hline \multicolumn{8}{|c|}{ Mother lived on farm while pregnant } \\
\hline No & 771 & Referent & & Referent & & Referent & \\
\hline Yes & 2250 & -16.6 (-59.1 to 26.0$)$ & 0.45 & $-11.7(-60.1$ to 36.6$)$ & 0.63 & $-0.6(-1.2$ to 0.1$)$ & 0.11 \\
\hline Missing & 40 & & & & & & \\
\hline \multicolumn{8}{|c|}{ Mother performed farm activities while pregnant } \\
\hline No & 940 & Referent & & Referent & & Referent & \\
\hline Yes & 1962 & $6.0(-33.8$ to 45.8$)$ & 0.77 & $-6.6(-51.9$ to 38.8$)$ & 0.78 & $0.3(-0.3$ to 1.0$)$ & 0.32 \\
\hline Missing & 159 & & & & & & \\
\hline \multicolumn{8}{|c|}{ Mother worked with farm animals while pregnant } \\
\hline No & 957 & Referent & & Referent & & Referent & \\
\hline Yes & 1863 & $-4.4(-44.4$ to 35.7$)$ & 0.83 & $-9.5(-55.2$ to 36.2$)$ & 0.68 & $0.2(-0.5$ to 0.8$)$ & 0.61 \\
\hline Missing & 241 & & & & & & \\
\hline \multicolumn{8}{|c|}{ Family lived on farm when born } \\
\hline No & 767 & Referent & & Referent & & Referent & \\
\hline Yes & 2259 & $-19.7(-62.3$ to 23.0$)$ & 0.37 & $-11.8(-60.2$ to 36.7$)$ & 0.63 & $-0.6(-1.3$ to 0.05$)$ & 0.07 \\
\hline Missing & 35 & & & & & & \\
\hline \multicolumn{8}{|c|}{ Farm animal exposure before age 3} \\
\hline No & 822 & Referent & & Referent & & Referent & \\
\hline Yes & 1958 & $-1.8(-43.4$ to 39.8$)$ & 0.93 & -9.1 (-56.6 to 38.3$)$ & 0.71 & $0.3(-0.4$ to 0.9$)$ & 0.46 \\
\hline Missing & 281 & & & & & & \\
\hline \multicolumn{8}{|c|}{ Farm animal exposure before age 6} \\
\hline No & 625 & Referent & & Referent & & Referent & \\
\hline Yes & 2314 & 3.5 (-42.2 to 49.2$)$ & 0.88 & $9.2(-42.8$ to 61.3$)$ & 0.73 & $0.01(-0.7$ to 0.7$)$ & 0.99 \\
\hline Missing & 122 & & & & & & \\
\hline \multicolumn{8}{|l|}{ Breast fed } \\
\hline No & 1057 & Referent & & Referent & & Referent & \\
\hline Yes & 1439 & 20.3 (-21.8 to 62.3$)$ & 0.35 & 20.1 (-27.7 to 67.9$)$ & 0.41 & $-0.2(-0.8$ to 0.5$)$ & 0.66 \\
\hline Missing & 565 & & & & & & \\
\hline \multicolumn{8}{|c|}{ Indoor furry pets before age 6} \\
\hline No & 2204 & Referent & & Referent & & Referent & \\
\hline Yes & 800 & $-7.3(-47.6$ to 33.1$)$ & 0.72 & $-34.7(-80.6$ to 11.2$)$ & 0.14 & $0.9(0.2$ to 1.5$)$ & 0.01 \\
\hline Missing & 57 & & & & & & \\
\hline \multicolumn{8}{|c|}{ Mother smoked cigarettes when pregnant } \\
\hline No & 2637 & Referent & & Referent & & Referent & \\
\hline Yes & 275 & -25.1 ( -87.5 to 37.3$)$ & 0.43 & $-11.6(-82.8$ to 59.7$)$ & 0.75 & $0.1(-0.9$ to 1.2$)$ & 0.77 \\
\hline Missing & 149 & & & & & & \\
\hline \multicolumn{8}{|c|}{ Parents smoked cigarettes in house before age 6} \\
\hline No & 1362 & Referent & & Referent & & Referent & \\
\hline Yes & 1611 & $-12.4(-48.9$ to 24.0$)$ & 0.50 & $-21.0(-62.4$ to 20.4$)$ & 0.32 & $0.4(-0.2$ to 1.0$)$ & 0.16 \\
\hline Missing & 88 & & & & & & \\
\hline \multicolumn{8}{|l|}{ Raw milk } \\
\hline No & 643 & Referent & & Referent & & Referent & \\
\hline Yes & 2246 & 49.5 (2.8 to 96.1$)$ & 0.04 & 66.2 (13.2 to 119.1$)$ & 0.01 & $0.4(-0.4$ to 1.1$)$ & 0.33 \\
\hline Missing & 172 & & & & & & \\
\hline
\end{tabular}

*Estimates represent the difference in mean response (FEV ${ }_{1}$ and FVC in millilitres and FEV $/ F V C$ as a percent) between a subject who experienced the exposure and one who did not, holding all covariates constant. Covariates were selected based on previous research on modelling pulmonary function and Agricultural Lung Health Study analyses and included age, age ${ }^{2}$, gender, race, state (lowa or North Carolina), height, height ${ }^{2}$, smoking status, pack-years, asthma status, and for FVC, weight. Cls were calculated as the beta coefficient plus or minus 1.96 times the standard error $(\beta \pm 1.96 \times \mathrm{SE})$. 
Table 2 Associations between raw milk exposure and pulmonary function in the Agricultural Lung Health Study, 2009-2013

\begin{tabular}{|c|c|c|c|c|c|c|c|}
\hline \multirow[b]{2}{*}{ Raw milk exposure } & \multirow[b]{2}{*}{$\mathbf{N}$} & \multicolumn{2}{|l|}{$\mathrm{FEV}_{1}(\mathrm{~mL})$} & \multicolumn{2}{|l|}{ FVC (mL) } & \multicolumn{2}{|l|}{$\mathrm{FEV}_{1} / \mathrm{FVC}(\%)$} \\
\hline & & $\boldsymbol{\beta}(95 \% \mathrm{Cl})^{*}$ & p Value & $\boldsymbol{\beta}(95 \% \mathrm{Cl})^{*}$ & p Value & $\boldsymbol{\beta}(95 \% \mathrm{Cl})^{*}$ & $p$ Value \\
\hline Total & 3061 & & & & & & \\
\hline Never drank raw milk & 643 & Referent & & Referent & & Referent & \\
\hline Start before age 6 & 1888 & $51.3(2.8$ to 99.8$)$ & 0.04 & $76.7(21.7$ to 131.7$)$ & 0.006 & $0.3(-0.5$ to 1.1$)$ & 0.51 \\
\hline \multicolumn{8}{|c|}{ Raw milk started before or after age 3} \\
\hline Never drank raw milk & 643 & Referent & & Referent & & Referent & \\
\hline Start before age 3 & 1688 & $51.1(1.6$ to 100.6$)$ & 0.04 & $74.3(18.2$ to 130.4$)$ & 0.01 & $0.3(-0.5$ to 1.1$)$ & 0.48 \\
\hline Start age 3 or after & 536 & $46.0(-11.0$ to 103.0$)$ & 0.11 & $53.9(-10.8$ to 118.5$)$ & 0.10 & $0.5(-0.4$ to 1.7$)$ & 0.31 \\
\hline Yes & 1781 & $28.3(-12.7$ to 69.3$)$ & 0.18 & $53.8(7.2$ to 100.5$)$ & 0.02 & $-0.1(-0.8$ to 0.5$)$ & 0.68 \\
\hline Missing & 107 & & & & & & \\
\hline \multicolumn{8}{|c|}{ Ever raw milk/main milk in childhood } \\
\hline Never drank raw milk & 643 & Referent & & Referent & & Referent & \\
\hline Drank raw but not main milk & 415 & $56.9(-3.8$ to 117.6$)$ & 0.07 & $60.6(-8.2$ to 129.5$)$ & 0.08 & $0.7(-0.3$ to 1.7$)$ & 0.19 \\
\hline Main milk was raw & 1781 & $45.2(-4.4$ to 94.8$)$ & 0.07 & 66.4 (10.1 to 122.7$)$ & 0.02 & $0.2(-0.6$ to 1.0$)$ & 0.56 \\
\hline Missing & 222 & & & & & & \\
\hline
\end{tabular}

*Estimates represent the difference in mean response (FEV and FVC in millilitres and FEV/FVC as a percent) between a subject who experienced the exposure and one who did not, holding all covariates constant. Covariates were selected based on previous research on modelling pulmonary function and Agricultural Lung Health Study analyses and included age, age ${ }^{2}$, gender, race, state (lowa or North Carolina), height, height ${ }^{2}$, smoking status, pack-years, asthma status, and for FVC, weight. Cls were calculated as the beta coefficient plus or minus 1.96 times the standard error $(\beta \pm 1.96 \times \mathrm{SE})$.

table 4). For FVC, the results differed little by gender (female: $\beta=68.1 \mathrm{~mL}, 95 \% \mathrm{CI}$ 14.4 to $121.8 \mathrm{~mL}$; male: $\beta=56.4 \mathrm{~mL}, 95 \%$ CI -40.4 to $\left.153.3 \mathrm{~mL} ; \mathrm{p}_{\text {interaction }}=0.19\right)$. No material differences by atopy status (defined as specific Immunoglobulin $\mathrm{E}$ (IgE) $>0.70 \mathrm{IU} / \mathrm{mL}$ to at least one of ten allergens measured in blood $^{3}$ ) or number of siblings (dichotomised into $0-2$ or $3+$, used as an indicator of exposure to infections in early-life ${ }^{10}$ ) were noted (see online supplementary table 4).

Childhood indoor furry pet exposure was associated with modestly higher $\mathrm{FEV}_{1} /$ FVC $(\beta=0.9 \%, 95 \%$ CI 0.2 to $1.5 \%$, $\mathrm{p}=0.01$; table 1 ). Aside from this, no other early-life farming exposures were associated with adult pulmonary function (table 1). Given the childhood furry pet association, we examined raw milk models additionally adjusted for that exposure, but found no evidence of confounding $\left(\mathrm{FEV}_{1}\right.$ : $\beta=49.7 \mathrm{~mL}, p=0.04 ;$ FVC: $\beta=67.9 \mathrm{~mL}$, $\mathrm{p}=0.01)$.

\section{DISCUSSION}

Childhood raw milk consumption was related to higher $\mathrm{FEV}_{1}$ and FVC in this older adult US farming population. Few previous studies have addressed the relationship between early-life farm exposure and $\mathrm{FEV}_{1}$ or FVC in adults, ${ }^{4-6}$ and none examined early-life raw milk consumption. The two largest studies-the European Community Respiratory Health Survey II (ECRHS II, $n=10201$ ) and a Finnish study $(n=5666)$-both found that being born or raised on a farm was associated with higher $\mathrm{FEV}_{1}$ and/or FVC. ${ }^{5}$ The ECRHS study specifically noted a stronger positive association between living on a farm in childhood and $\mathrm{FEV}_{1}$ in women than in men, ${ }^{4}$ similar to our finding of a slightly stronger raw milk$\mathrm{FEV}_{1}$ association in women.

Although we found positive associations of raw milk consumption with both $\mathrm{FEV}_{1}$ and FVC, we did not see an association with $\mathrm{FEV}_{1} / \mathrm{FVC}$, suggesting that the beneficial effect of raw milk is predominantly on lung growth rather than airway calibre. In support of this hypothesis, we did not see an effect of raw milk consumption on either adult non-atopic asthma or atopic asthma (both compared with individuals with neither asthma nor atopy) in a previous publication. ${ }^{3}$ We also observed a slight increase in $\mathrm{FEV}_{1} / \mathrm{FVC}$ for indoor furry pets before age 6 years. However, in a previous publication we did not find a protective association between indoor furry pets before age 6 years and either asthma, atopy or their combination. ${ }^{3}$

Mechanisms of our observed association are speculative. Differences in the nutrient composition of raw and commercial milk, including total fat content and specific fatty acid composition, ${ }^{2}$ could theoretically influence rates of growth, including the lungs, in childhood. Raw milk contains micro-organisms absent from pasteurised commercial milk; some may influence the developing immune system in ways that could account for the reported protective effect of early raw milk consumption on allergic disease. ${ }^{2}$ Several studies have reported that raw milk consumption in pregnancy or childhood leads to greater production of interferon $\gamma($ IFN $\gamma)$ in children. ${ }^{211}$ In a US birth cohort, higher IFN $\gamma$ production by stimulated peripheral blood mononuclear cells at age 1 year was related to higher $\mathrm{FEV}_{1}$ and FVC, but not $\mathrm{FEV}_{1} / \mathrm{FVC}$, at age 8 . $^{12}$ Elevated IFN $\gamma$ may protect young children against airway infections, contributing to better pulmonary function in adulthood.

As described in detail in a previous ALHS paper, ${ }^{3}$ we sought to enhance the quality of information about early-life exposures 
by sending participants questionnaires in advance of home visits, encouraging participants to speak with family members (eg, siblings) and asking about exposures by 6 years of age when memories are more reliably formed. Although we could not directly assess selective entry into our study based on raw milk consumption and pulmonary function, we performed a quantitative selection bias analysis ${ }^{13}$ based on childhood farm animal exposure and asthma in a previous publication $^{3}$; we did not find evidence for selection bias from AHS into ALHS. Nevertheless, a biased association could still result if choosing to remain in farming before the initial AHS enrolment period (1993-1997) was jointly related to early-life raw milk consumption and better pulmonary function. Finally, we had limited ability to assess duration of raw milk consumption in the minority who started after age 6 and lacked data on the quantity consumed.

Previous literature examining the hygiene hypothesis in farm environments has identified protective associations with in utero and childhood exposures using several metrics, including farm animal contact and farm work performed by mothers while pregnant, residing on a farm at birth or in childhood, and farm animal contact and farm work performed by individuals during childhood. $^{12}$ Our study examined similar metrics which, not surprisingly, were highly correlated. The first six variables in table 1 had tetrachoric correlations ranging from 0.84 to 0.99 in ALHS. ${ }^{3}$ However, raw milk consumption-the only farming variable that we found to be related to pulmonary function-was less strongly correlated with the other farm variables, with correlations ranging from 0.47 to $0.55 .^{3}$ In addition, pulmonary function parameters were correlated with each other to varying degrees; partial correlations, adjusted for age, height, gender and race, were 0.84 for $\mathrm{FEV}_{1}$ with FVC, 0.60 for $\mathrm{FEV}_{1}$ with the $\mathrm{FEV}_{1} / \mathrm{FVC}$, and 0.15 for FVC with $\mathrm{FEV}_{1} /$ FVC. Given the hypothesis-driven nature of our research ${ }^{14} 15$ and the correlations of several early-life farming exposures as well as pulmonary function measures, we did not correct for multiple comparisons, thereby increasing the possibility of false-positives but reducing the risk of false-negatives.

A strength of our study is the large farming population of older adults, allowing us to assess possible persistence of associations across the life course in the USA. Our data suggest that raw milk consumption, particularly early in life, is associated with better pulmonary function in adulthood.
Annah B Wyss, ${ }^{1}$ John S House, ${ }^{2,3}$ Jane A Hoppin, ${ }^{4}$ Marie Richards, ${ }^{5}$ John L Hankinson, ${ }^{6}$ Stuart Long, ${ }^{5}$ Paul K Henneberger, ${ }^{7}$ Laura E Beane Freeman, ${ }^{8}$ Dale P Sandler, ${ }^{1}$ Elizabeth Long $\mathrm{O}^{\prime}$ Connell, ${ }^{9}$ Christie Barker Cummings, ${ }^{9}$ David M Umbach, ${ }^{10}$ Stephanie J London ${ }^{1,2}$

${ }^{1}$ Epidemiology Branch, National Institute of Environmental Health Sciences, National Institutes of Health, Department of Health and Human Services, Research Triangle Park, North Carolina, USA ${ }^{2}$ Immunity, Inflammation and Disease Laboratory, National Institute of Environmental Health Sciences, National Institutes of Health, Department of Health and Human Services, Research Triangle Park, North Carolina, USA

${ }^{3}$ Bioinformatics Research Center, North Carolina State University, Raleigh, North Carolina, USA

${ }^{4}$ Department of Biological Sciences, Center for Human Health and the Environment, North Carolina State University, Raleigh, North Carolina, USA

${ }^{5}$ Westat, Durham, North Carolina, USA

${ }^{6}$ Hankinson Consulting, Inc., Valdosta, Georgia, USA ${ }^{7}$ Respiratory Health Division, National Institute for Occupational Safety and Health, Centers for Disease Control and Prevention, Morgantown, West Virginia, USA

${ }^{8}$ Occupational and Environmental Epidemiology Branch, National Cancer Institute, Bethesda, Maryland, USA ${ }^{9}$ Epidemiology Center, Public Health Sciences Group, Social \& Scientific Systems, Durham, North Carolina, USA

${ }^{10}$ Biostatistics and Computational Biology Branch, National Institute of Environmental Health Sciences, National Institutes of Health, Department of Health and Human Services, Research Triangle Park, North Carolina, USA

Correspondence to Dr Stephanie J London, National Institute of Environmental Health Sciences, PO Box 12233, MD A3-05, Research Triangle Park, NC 27709, USA; london2@niehs.nih.gov

Acknowledgements We thank the numerous study staff at Social \& Scientific Systems, who played a role in the data collection. The findings and conclusions in this report are those of the authors and do not necessarily represent the views of the National Institute for Occupational Safety and Health (NIOSH). Mention of any company or product does not constitute endorsement by NIOSH.

Contributors All authors meet the ICMJE recommendations for authorship (ie, all authors contributed to the conception/design of the study or the acquisition/analysis/interpretation of the data and assisted in drafting/revising the manuscript, including approving the manuscript for submission).

Funding This work was supported by the intramural research program of the $\mathrm{NIH}$, National Institute of Environmental Health Sciences (NIEHS) (Z01-ES049030 and ZO1-ES102385) and National Cancer Institute (NCI) (Z01-CP010119). This work was also supported in part by American Recovery and Reinvestment Act (ARRA) funds through NIEHS contract number NO1ES-55546.

\section{Competing interests None declared.}

Ethics approval US National Institutes of Health.

Provenance and peer review Not commissioned; externally peer reviewed.

(c) Article author(s) (or their employer(s) unless otherwise stated in the text of the article) 2018. All rights reserved. No commercial use is permitted unless otherwise expressly granted.
Additional material is published online only. To view please visit the journal online (http://dx.doi.org/ 10.1136/thoraxjnl-2017-210031)

\section{Check for updates}

To cite Wyss AB, House JS, Hoppin JA, et al. Thorax 2018:73:279-282.

Received 20 January 2017

Revised 14 April 2017

Accepted 1 May 2017

Published Online First 8 July 2017

Thorax 2018:73:279-282.

doi:10.1136/thoraxjnl-2017-210031

\section{REFERENCES}

1 von Mutius E, Vercelli D. Farm living: effects on childhood asthma and allergy. Nat Rev Immunol 2010;10:861-8

2 Braun-Fahrländer C, von Mutius E. Can farm milk consumption prevent allergic diseases? Clin Exp Allergy 2011:41:29-35.

3 House JS, Wyss AB, Hoppin JA, et al. Early-life farm exposures and adult asthma and atopy in the Agricultural Lung Health Study. J Allergy Clin Immunol 2017; 140:249-56.

4 Campbell B, Raherison C, Lodge CJ, et al. The effects of growing up on a farm on adult lung function and allergic phenotypes: an international population-based study. Thorax 2017;72:236-44.

5 Lampi J, Koskela H, Hartikainen AL, et al. Farm environment during infancy and lung function at the age of 31: a prospective birth cohort study in Finland. BMJ Open 2015;5:e007350.

6 Schulze A, van Strien RT, Praml G, et al. Characterisation of asthma among adults with and without childhood farm contact. Eur Respir J 2007:29:1169-73.

7 Carnes MU, Hoppin JA, Metwali N, et al. House dust endotoxin levels are associated with adult asthma in a US Farming Population. Ann Am Thorac Soc 2017;14:324-31.

8 Hankinson JL, Eschenbacher B, Townsend M, et al. Use of forced vital capacity and forced expiratory volume in 1 second quality criteria for determining a valid test. Eur Respir J 2015;45:1283-92.

9 Hankinson JL, Odencrantz JR, Fedan KB. Spirometric reference values from a sample of the general U.S. population. Am J Respir Crit Care Med 1999;159:179-87.

10 Loss G, Depner M, Ulfman LH, et al. Consumption of unprocessed cow's milk protects infants from common respiratory infections. J Allergy Clin Immunol 2015;135:56-62.

11 Kääriö H, Huttunen K, Karvonen AM, et al. Exposure to a farm environment is associated with T helper 1 and regulatory cytokines at age 4.5 years. Clin Exp Allergy 2016:46:71-7.

12 Shutes B, Stern DA, Wright A, et al. Impact of early life interferon gamma levels on lung development in childhood: a birth cohort analysis. Am J Respir Crit Care Med 2016;193:A6689.

13 Lash TL, Fox MP, Fink AK. Applying quantitative bias analysis to epidemiologic data. New York, NY: Springer, 2009.

14 Savitz DA, Olshan AF. Multiple comparisons and related issues in the interpretation of epidemiologic data. Am J Epidemiol 1995;142:904-8.

15 Goldberg M, Silbergeld E. On multiple comparisons and on the design and interpretation of epidemiological studies of many associations. Environ Res 2011;111:1007-9. 